\title{
Bond strength of a resin cement to dentin using the resin coating technique
}

\section{Claudia Batitucci dos \\ Santos-Daroz ${ }^{(a)}$}

Marcelo Tavares Oliveira ${ }^{(b)}$ Mário Fernando de Góes ${ }^{(c)}$ Toru Nikaido(d) Junji Tagami ${ }^{(e)}$ Marcelo Giannini ${ }^{(f)}$

\footnotetext{
(a) Graduate Student (Master's degree); (b) Graduate Student (Doctorate degree); (c) Professor; (f) Associate Professor - Department of Restorative Dentistry, Piracicaba Dental School, State University of Campinas, Piracicaba, SP, Brazil.

(d) Lecturer; (e)Professor - Department of Restorative Sciences, Graduate School, Tokyo Medical and Dental University, Tokyo, Japan.
}

\begin{abstract}
The aim of this study was to evaluate the bond strength of a resin cement to dentin using different adhesive systems (AS) in the presence or absence of a low-viscosity composite liner (Protect Liner F - PLF) applied over the bonded dentin. The adhesive systems selected were: AdheSE/Vivadent (AD); Clearfil Protect Bond/Kuraray (CP); One-Up Bond F/Tokuyama (OU); Single Bond/3M ESPE (SB); Tyrian SPE/One-Step Plus/Bisco (TY); Xeno III/Dentsply (XE) and Unifil Bond/GC (UN). After removing the labial and lingual enamel surfaces of bovine incisors, dentin fragments were prepared and randomly divided into 15 groups $(\mathrm{n}=8)$. The dentin substrates were bonded with the AS and the PLF was applied or not before application of the resin cement (Panavia F, Kuraray). In the control group, the ED Primer (ED) and the resin cement without PLF were used. The AS, PLF and resin cement tested were used according to the manufacturers' instructions, and all treated dentin surfaces were temporized. After water storage for one week, three cylinders of resin cement were applied to each bonded dentin surface, using tygon tubing molds. The specimens were subjected to micro-shear testing and the data were statistically analyzed (two-way ANOVA, Tukey and Dunnett tests, $\mathrm{p}<0.05)$. The observed mean shear bond strengths in $\mathrm{MPa}$ were: ED: $20.2 \pm 2.3$; AD: $30.3 \pm 6.5$; CP: $25.3 \pm 4.4$; OU: $28.3 \pm 6.6$; SB: $25.6 \pm 6.9$; TY: $24.5 \pm 2.5$; XE: $17.3 \pm 3.4$; UN: $28.4 \pm 6.2$; AD+PLF: $32.8 \pm 4.1$; CP+PLF: $29.9 \pm 3.9$; OU+PLF: $34.1 \pm 4.1$; SB+PLF: $29.5 \pm 8.2$; TY+PLF: $29.2 \pm 3.9$; XE+PLF: $32.8 \pm 6.7$; UN+PLF: $32.2 \pm 4.5$. The bond strength of the resin cement to dentin using the tested AS was increased when the low-viscosity composite liner was applied.
\end{abstract}

Descriptors: Dentin-bonding agents; Dentin; Shear strength; Composite resins.

\author{
Corresponding author: \\ Marcelo Giannini \\ Av. Limeira, 901 - Areião \\ Piracicaba - SP - Brazil \\ CEP: 13414-018 \\ E-mail: giannini@fop.unicamp.br
}

Received for publication on Nov 16, 2006

Accepted for publication on Jun 20, 2007 


\section{Introduction}

Resin cement materials are commonly recommended for the cementation of metal-free inlays, onlays, laminates and full crowns, because of their adhesion properties to both tooth structures and restorative materials, as well as their low solubility (if well polymerized), longer work time and aesthetic characteristics. ${ }^{1}$ Nevertheless, the high polymerization shrinkage of resin cements may disrupt the bond between cement and tooth surface or restorative material, which can be responsible for marginal infiltration, post-operative pain and premature debonding of the restoration. ${ }^{2,3}$ Furthermore, the selection of the adhesive system may contribute to a cementation failure because of some chemical incompatibilities between acidic monomers and chemically- or dual-cured resin based materials. ${ }^{4,5}$

The resin coating technique was initially developed to protect the exposed, intact dentin after tooth preparation from saliva contamination. ${ }^{6}$ Moreover, this technique can overcome the incompatibility problems during cementation, improving the bond strength of dual-cured resin cements to dentin and the interfacial adaptation of indirect restorations. ${ }^{1,2,4}$ The technique consists of a hybridization of dental substrates with the application of a bonding agent followed by a low viscosity micro-filled resin over bonded surfaces. ${ }^{7}$ Specific adhesive systems have been tested with a resin coating technique, ${ }^{1,2,4,7}$ however, other commercially available systems can also be used with this restorative technique and need to be evaluated. These systems are adhesive resin solutions of different $\mathrm{pHs}$ and monomeric compositions, which can be incompatible with the dual-cured characteristics of resin cements or with low-viscosity resins. ${ }^{6,8}$

The purpose of this study was to evaluate the bond strength of a dual-cured resin cement to dentin using different adhesive systems in the absence or presence of a low-viscosity composite liner, simulating the resin coating technique. The hypothesis tested was that the low-viscosity composite application would influence the bond strength of the different adhesive systems to dentin.

\section{Material and Methods}

Sixty freshly extracted, bovine incisors stored at $6^{\circ} \mathrm{C}$ were used in this study. The roots, and lingual and labial enamel were removed using a diamond disk (Isomet, Buehler, Evanstone, IL, USA) under water-cooling. Each flat buccal dentin surface of the crown was sectioned longitudinally and divided into two parts with similar size (12 mm in length $\mathrm{x} 5 \mathrm{~mm}$ in width $\times 1.5 \mathrm{~mm}$ in thickness) (Figure 1A). The dentin surfaces were wet-abraded with 600-grit SiC paper (Carburundum, Vinhedo, SP, Brazil) to create a standardized smear layer and then the dentin fragments were randomly divided into 15 groups $(\mathrm{n}=8)$.

Eight adhesive systems (Table 1): an etch \& rinse simplified system (Single Bond, 3M ESPE, St. Paul, MN, USA), three one-step self-etching systems (ED Primer, Kuraray Medical Inc., Kurashiki, Japan; One-Up Bond F, Tokuyama Dental Corp., Tokyo, Japan; Xeno III, Dentsply DeTrey, Konstanz, Germany) and four 2-step self-etching systems (AdheSE, Ivoclar Vivadent, Schaan, Liechtenstein; Clearfil Protect Bond, Kuraray Medical Inc., Kurashiki, Japan; Tyrian SPE/One-Step Plus SPE, Bisco Inc., Schaumburg, IL, USA; Unifil Bond, GC Corp., Tokyo, Japan); a dual-cured resin cement (Panavia F, Kuraray Medical Inc., Kurashiki, Japan); and a low-viscosity microfilled composite (Protect Liner F, Kuraray Medical Inc., Kurashiki, Japan) were evaluated. Adhesive systems, resin cement and lowviscosity resin were applied according to the manufacturers' instructions.

For group 1 (control group), the dentin surfaces were kept untreated. In groups 2 (AdheSE), 4 (Clearfil Protect Bond), 6 (One-Up Bond F), 8 (Single Bond), 10 (Tyrian SPE/One-Step Plus), 12 (Unifil Bond) and 14 (Xeno III), the dentin surfaces were only treated with the adhesive systems. For groups 3 (AdheSE), 5 (Clearfil Protect Bond), 7 (One-Up Bond F), 9 (Single Bond), 11 (Tyrian SPE/One-Step Plus SPE), 13 (Unifil Bond) and 15 (Xeno III), the low-viscosity resin was applied as a thin coat over the adhesive resin layer and light-cured for $20 \mathrm{sec}-$ onds. The methodology developed by Shimada et al. ${ }^{9}$ (2002) and modified by Giannini et al. ${ }^{4}$ (2004) was used to prepare specimens for the micro-shear test. All light-curing procedures were performed with the XL 3000 curing unit (3M ESPE, St. Paul, $\mathrm{MN}$, USA), under standard irradiation mode and 
$650 \mathrm{~mW} / \mathrm{cm}^{2}$. Untreated surfaces from group 1 and bonded dentin surfaces were temporized with noneugenol zinc oxide material (Temp Bond NE, Kerr Corp., Orange, CA, USA) and the samples were stored in water at $37^{\circ} \mathrm{C}$ (Figure $1 \mathrm{~B}$ ).

After one week of storage, the temporary material was removed and the ED Primer was applied in dentin (group 1), over bonded dentin (groups 2, 4, 6, 8, 10, 12 and 14) and over resin coated dentin (groups $3,5,7,9,11,13$ and 15). Three cylindrical translucent molds (Tygon tubing, TYG-030, Saint-Gobain Performance Plastic, Maime Lakes, FL, USA) were positioned over the treated dentin of each dentinal sample, and a freshly mixed dual-cure resin cement (Panavia F, Kuraray Medical Inc., Kurashiki, Japan) was placed in the molds to fill their internal volume, using a modified composite spatula (Duflex \# 3, SS White, Juiz de Fora, MG, Brazil).

The restored dental fragments were stored in water at $37^{\circ} \mathrm{C}$ for $24 \mathrm{~h}$. The tube molds were removed to expose the resin cement cylinders $(0.75 \mathrm{~mm}$ in diameter by $0.5 \mathrm{~mm}$ in height) bond- ed to the dentin surface, thus, three bonded small resin cement cylinders were obtained for each dentinal sample. Before the test, all resin cylinders were checked under an optical microscope $(30 \mathrm{X}$, EMZ-TR, Meiji Techno Co., Saitama, Japan) for bonding defects.

Each dentinal sample was attached to the testing device with cyanoacrylate glue (Super Bonder, Loctite, Itapevi, SP, Brazil) and tested in a universal testing machine (4411, Instron Corp., Canton, MA, USA). A shear load was applied to the base of the resin cement cylinder with a thin wire $(0.20 \mathrm{~mm}$ in diameter) at a crosshead speed of $0.5 \mathrm{~mm} / \mathrm{min}$ until failure (Figure 1C). The shear bond strengths were calculated and expressed in $\mathrm{MPa}$. Three bond strength measurements were recorded for each dental fragment and the mean bond strength was determined for each experimental unit. The results were analyzed statistically by two-way analysis of variance (ANOVA) and Tukey test at the 5\% level of significance (adhesive system $\mathrm{X}$ resin coating). Additional treatment with Dunnett's test was applied

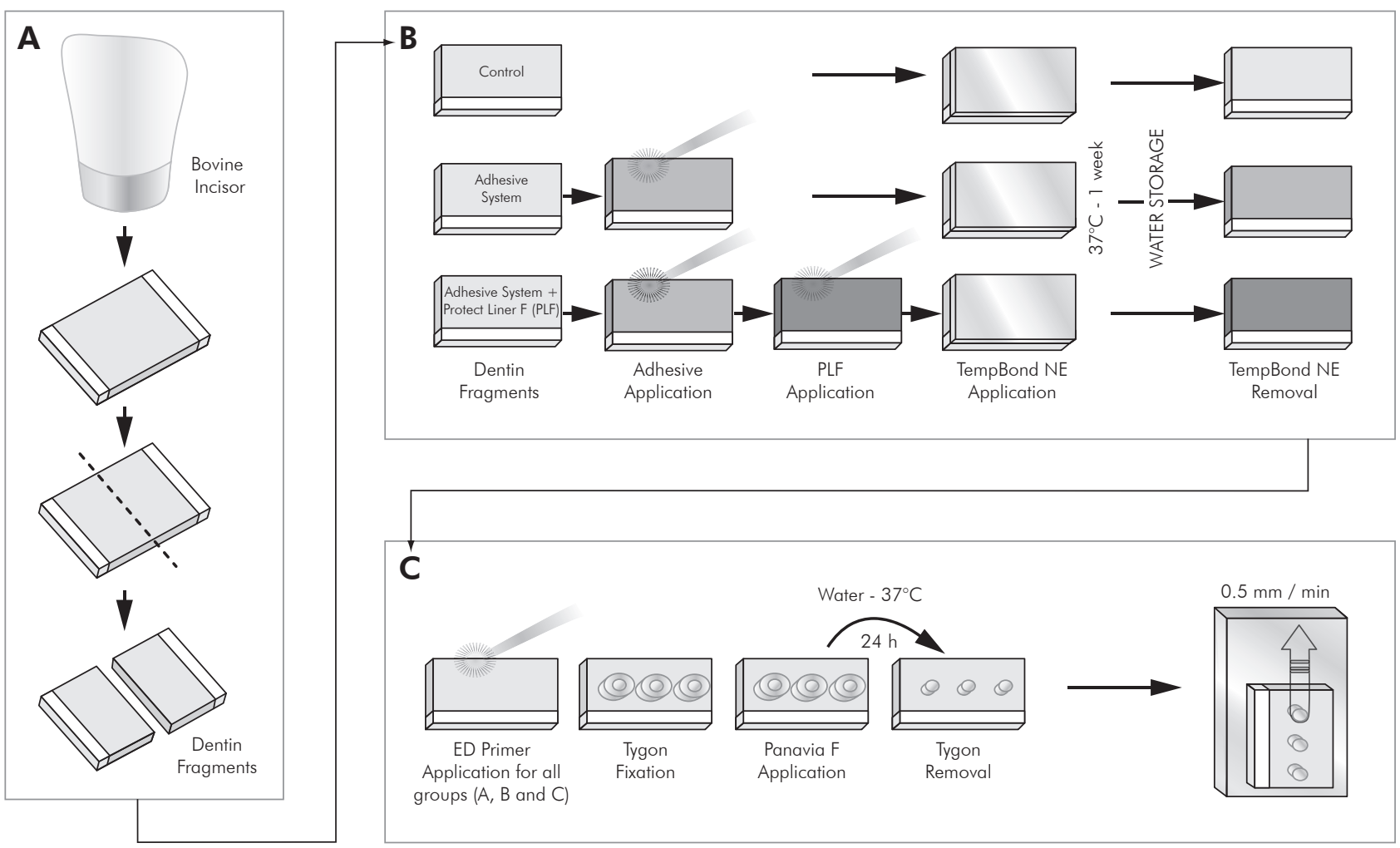

Figure 1 - Schematic representation of specimen preparation. 
for the control group.

After testing, the debonded dentin samples were mounted on aluminum stubs, gold-sputter coated (SCD 050, Baltec, Vaduz, Liechtenstein) and examined using a scanning electron microscope (JSM5600LV, Jeol, Tokyo, Japan). Photomicrographs of representative areas of the fractured surfaces were

Table 1 - Compositions of the adhesive systems used in this study.

\begin{tabular}{|c|c|}
\hline $\begin{array}{l}\text { Adhesive } \\
\text { System }\end{array}$ & Composition \\
\hline $\begin{array}{l}\text { AdheSE } \\
(\mathrm{pH} 1.7)\end{array}$ & $\begin{array}{l}\text { Primer: dimethacrylate, phosphonic acid } \\
\text { acrylate, initiators and stabilizer, water. } \\
\text { Bonding resin: HEMA, dimethacrylates, silicon } \\
\text { dioxide, initiators and stabilizer. }\end{array}$ \\
\hline $\begin{array}{l}\text { Clearfil } \\
\text { Protect Bond } \\
(\mathrm{pH} 2.5)\end{array}$ & $\begin{array}{l}\text { - Primer: Water, MDPB, HEMA, } \\
\text { dimethacrylates, photoinitiator. } \\
\text { - Bonding resin: MDP, HEMA, dimethacrylates, } \\
\text { silanated colloidal silica, NaF. }\end{array}$ \\
\hline $\begin{array}{l}\text { ED Primer } \\
(\mathrm{pH} 2.4)\end{array}$ & $\begin{array}{l}\text { - Primer A: 10-Methacryloyloxydecyl } \\
\text { Dihydrogen Phosphate; HEMA, Ethylene } \\
\text { Glycol Methacrylate; N, N-Di-(2- } \\
\text { Hydroxyethyl)-P-Tolvidine; 5-NMSA; Water. } \\
\text { - Primer B: Benzenesulfinic Acid, Sodium Salt; } \\
\text { N, N-Di-(2-Hydroxyethyl)-P-Toluidine; 5- } \\
\text { NMSA; Water }\end{array}$ \\
\hline $\begin{array}{l}\text { One-Up } \\
\text { Bond F } \\
(\mathrm{pH} 2.6)\end{array}$ & $\begin{array}{l}\text { Bonding A: Water, MMA, HEMA, coumarin } \\
\text { dye, metacryloyloxyalkyl acid phosphate, } \\
\text { MAC- } 10 \text {. } \\
\text { Bonding B: multifunctional methacrylic } \\
\text { monomer, fluoraluminosilicate glass, } \\
\text { photoinitiator (arylborate catalyst) }\end{array}$ \\
\hline $\begin{array}{l}\text { Single Bond } \\
(\mathrm{pH} 4.3)\end{array}$ & $\begin{array}{l}\text { - Etchant: } 35 \% \text { phosphoric acid. } \\
\text { - Primer \& Bonding resin: Bis-GMA, HEMA, } \\
\text { ethanol, water, UDMA, Bisphenol A } \\
\text { glycerolate, polyalkenoic acid copolymer, } \\
\text { dimethacrylate, camphorquinone. }\end{array}$ \\
\hline $\begin{array}{l}\text { Tyrian SPE/ } \\
\text { One-Step } \\
\text { Plus } \\
\text { (pH 0.5) }\end{array}$ & $\begin{array}{l}\text { - Primer: 2-Acrylamido-2-methyl } \\
\text { propanesulfonic acid, Bis [2-(methacryloyloxy) } \\
\text { ethyl] phosphate, ethanol. } \\
\text { - Primer \& Bonding resin: Biphenyl } \\
\text { dimethacrylate, hydroxyethyl methacrylate, } \\
\text { acetone, glass frit. }\end{array}$ \\
\hline $\begin{array}{l}\text { Unifil Bond } \\
\text { (pH 2.2) }\end{array}$ & $\begin{array}{l}\text { - Primer: HEMA, 4-MET, ethanol, water. } \\
\text { - Bonding resin: UDMA, HEMA, TEGDMA, } \\
\text { silanated colloidal silica. }\end{array}$ \\
\hline $\begin{array}{l}\text { Xeno III } \\
(\mathrm{pH} 1.4)\end{array}$ & $\begin{array}{l}\text { - Liquid A: HEMA, purified water, ethanol, } \\
\text { butylated hydroxy tolvene, highly dispersed } \\
\text { silicon dioxide. } \\
\text { - Liquid B: phosphoric acid functionalised } \\
\text { polymethacrylate resins, di- and } \\
\text { polyfunctionalised methacrylate resins, } \\
\text { butylated hidroxy tolvene, camphorquinone, } \\
\text { 4-dimethylamino-ethyl-benzoate. }\end{array}$ \\
\hline
\end{tabular}

taken at $100 \mathrm{X}$ to $300 \mathrm{X}$ magnifications and the failure mode was classified into one of the following types:

- Type 1: adhesive failure between bonding agent and dentin and between bonding agent and resin cement;

- Type 2: mixed failure, involving adhesive failure and cohesive failure in resin cement;

- Type 3: mixed failure, involving adhesive failure and cohesive failure in low-viscosity resin;

- Type 4: mixed failure, involving cohesive failure in dentin.

\section{Results}

The mean shear bond strength and standard deviation values are shown in Table 2 . Two-way ANOVA indicated that there was at least a statistically significant difference among the mean bond strength values of the experimental groups evaluated $(\mathrm{F}=16.33$ and $\mathrm{p}<0.0001)$. However, ANOVA failed to identify any factor interactions $(\mathrm{F}=0.49$; $\mathrm{p}=0.8450)$. Tukey's test showed that the bond strength of all adhesive systems/resin cement to dentin were significantly higher with the application of a low-viscosity resin layer over the bonded dentin than without the resin coating technique. The adhesive Xeno III had the lowest bond strength without application of the resin coating technique, while no

Table 2 - Mean bond strength (SD) values for the experimental groups (MPa).

\begin{tabular}{l|c|c}
\hline Adhesive System & $\begin{array}{c}\text { Without Resin } \\
\text { Coating [group] } \\
\text { [2] } 30.3(6.5) \mathrm{Ab}^{*}\end{array}$ & $\begin{array}{c}\text { With Resin } \\
\text { Coating [group] }\end{array}$ \\
\hline AdheSE & [32.8 (4.1) Aa* \\
\hline $\begin{array}{l}\text { Clearfil Protect } \\
\text { Bond }\end{array}$ & {$[4] 25.3(4.4) \mathrm{Ab}$} & {$[5] 29.9$ (3.9) Aa* } \\
\hline One-Up Bond F & {$[6] 28.3(6.6) \mathrm{Ab}$} & {$[7] 34.1$ (4.1) Aa* } \\
\hline Single Bond & {$[8] 25.6(6.9) \mathrm{Ab}$} & {$[9] 29.5(8.2) \mathrm{Aa}$} \\
\hline $\begin{array}{l}\text { Tyrian SPE/ } \\
\text { One-Step Plus }\end{array}$ & {$[10] 24.5(2.5) \mathrm{Ab}$} & {$[11] 29.2(3.9) \mathrm{Aa}^{*}$} \\
\hline Unifil Bond & {$[12] 28.4(6.2) \mathrm{Ab}$} & {$[13] 32.2(4.5) \mathrm{Aa}^{*}$} \\
\hline Xeno III & {$[14] 17.3(3.4) \mathrm{Bb}$} & {$[15] 32.8(6.7) \mathrm{Aa}^{*}$} \\
\hline
\end{tabular}

Control group [group 1]: 20.2 (2.3). *Significant differences from the control group by Dunnett's test $(p<0.05)$. Means followed by different letters (lower case - row; upper case - column) are significantly different by Tukey's test $(p<0.05)$. 
difference among adhesive systems were observed using the resin coating. Dunnett's test indicated that the shear bond strength of ED primer/resin cement to dentin (group 1) was similar to that of all the adhesive systems tested without resin coating, except for AdheSE. Tyrian SPE/One-Step Plus and Single Bond with resin coating were also similar to the ED Primer/Panavia F cementing system (group 1).

SEM examination of the fractured interfaces showed variations among groups (Table 3). Fractographic analysis of the dentin bonded with the ED Primer only (group 1) showed that the most frequent failure pattern observed was type 1 (Figure 2). Without the low-viscosity resin, fractures involved adhesive failure and partial cohesive failure in the resin cement (Figure 3). The use of the resin coating technique modified the failure pattern of the tested specimens, and the observed fractures involved a cohesive failure in the low-viscosity resin (Figure 4). All groups presented cohesive failures in dentin. Type 4 (Figure 5), however, was the most predominantly observed failure mode in the groups without

Table 3 - Failure modes (\%) of the tested specimens.

\begin{tabular}{c|c|c|c|c}
\hline Group & Type 1 & Type 2 & Type 3 & Type 4 \\
\hline 1 & 65 & 25 & 0 & 10 \\
\hline 2 & 30 & 30 & 0 & 40 \\
\hline 3 & 0 & 0 & 90 & 10 \\
\hline 4 & 55 & 10 & 0 & 35 \\
\hline 5 & 0 & 0 & 85 & 15 \\
\hline 6 & 20 & 30 & 0 & 50 \\
\hline 7 & 0 & 0 & 90 & 10 \\
\hline 8 & 30 & 50 & 0 & 20 \\
\hline 9 & 0 & 15 & 70 & 15 \\
\hline 10 & 40 & 10 & 0 & 50 \\
\hline 11 & 5 & 10 & 80 & 5 \\
\hline 12 & 20 & 10 & 0 & 70 \\
\hline 13 & 0 & 0 & 100 & 0 \\
\hline 14 & 20 & 35 & 0 & 45 \\
\hline 15 & 5 & 0 & 90 & 5 \\
\hline
\end{tabular}

Type 1: adhesive failure between bonding agent and dentin and between bonding agent and resin cement; Type 2: mixed failure, involving adhesive failure and cohesive failure in the resin cement; Type 3: mixed failure, involving adhesive failure and cohesive failure in the low-viscosity resin and Type 4: mixed failure, involving cohesive failure in dentin. application of the low-viscosity resin.

\section{Discussion}

The bond strength of a dual-cured resin cement to dentin using different adhesive systems in the presence of a low-viscosity composite liner was significantly higher than that obtained with the use of the dentin bonding systems alone. The resin coating technique has been shown to be efficient. The additional application of a low-viscosity microfilled resin can protect and promote an improvement of the polymerization of the underlying adhesive, resulting in an increase in bond strength. ${ }^{2,10}$

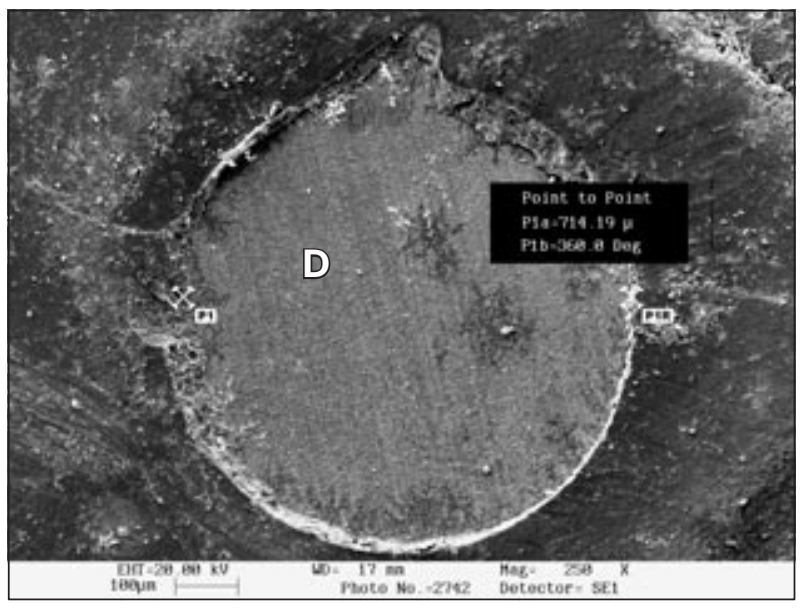

Figure 2 - Adhesive failure between bonding agent and resin cement [Dentin (D)].

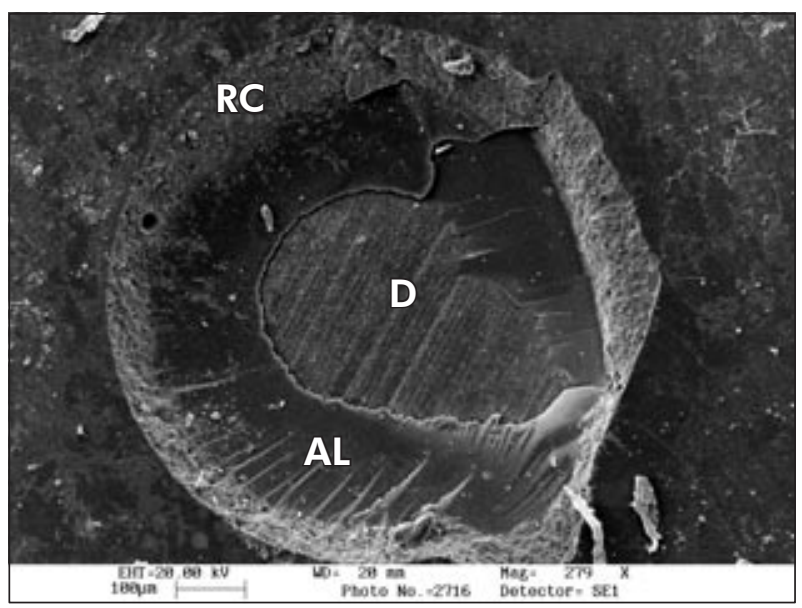

Figure 3 - Mixed failure, involving adhesive failure [Adhesive Layer (AL), Dentin (D)] and partial cohesive failure in the resin cement $(\mathbf{R C})$. 


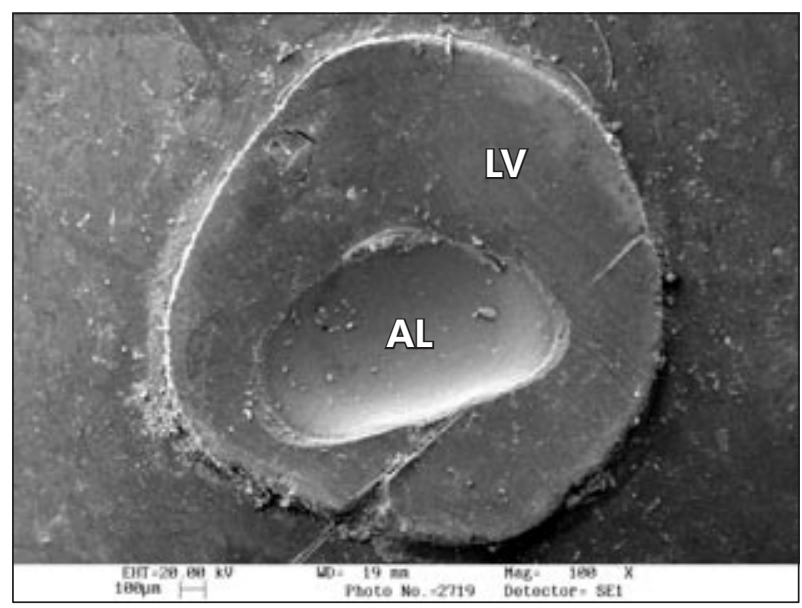

Figure 4 - Mixed failure, showing the low-viscosity resin $(\mathbf{L V})$ and the adhesive Layer $(\mathbf{A L})$.

Current one-step self-etching adhesive systems present highly acidic and hydrophilic resin monomers that simultaneously demineralize and infiltrate the dentin surface to form the hybrid layer. ${ }^{6}$ These acidic monomers do not completely convert to polymers as the oxygen and water may impair their total conversion. ${ }^{10}$ The presence of acidic monomers can prevent the proper polymerization of chemically or dual cured resin materials by the deactivation of the basic amines, affecting their bonding to the adhesive layer. ${ }^{4,5}$ Thus, the liner application eliminates the incompatibility area between resin-based materials, thus avoiding the formation of a weakened bonded interface. ${ }^{11}$ Moreover, the acidic monomers are more prone to attract water; therefore the adhesive layer formed by modern single bottle total-etch and onestep self-etching adhesive systems may work as a permeable membrane that allows fluids from the dentinal tubules to rise to the adhesive surface, thus affecting their accurate coupling to chemically or dual cured resin cements. ${ }^{6,8}$

The Panavia F resin cement used in this study presents in its chemical composition sodium benzene sulphinate, and the ED Primer solution contains sodium aromatic sulphinate to ensure that the polymerization reaction of the cementing system occurs even without light exposure. ${ }^{1,3}$ However, the low bond strength that was observed when this resin cement was applied to dentin without resin coating may be explained by the formed hybridization pro-

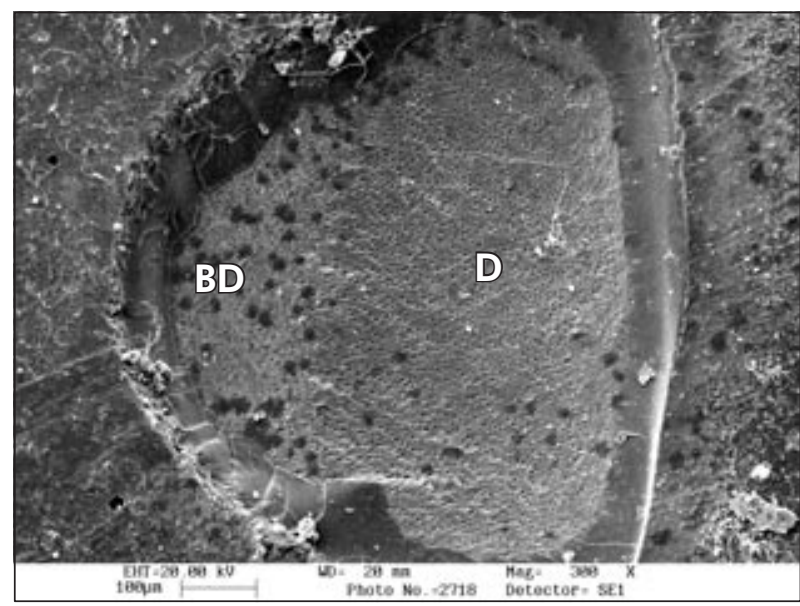

Figure 5 - Mixed failure, involving cohesive failure in dentin (D) and bonded dentin (BD).

cess and the increase in permeability associated with the one-step self-etching ED Primer. ${ }^{6,8,11}$ The tested specimens presented predominantly adhesive failure between bonding agent and dentin, demonstrating the weakness of the bonded interface created with the ED Primer (Figure 2).

Other one-step self-etching systems (One-Up Bond $\mathrm{F}$ and Xeno III) had a higher percentage of bond strength increase among the adhesives tested (20.5\% and $89.6 \%$, respectively), showing the importance of hydrophobic resin application over primed dentin, such as that used by the 2-step self-etching systems tested (AdheSE, Clearfil Protect Bond and Unifil Bond). However, the Xeno III single-step self-etching adhesive presents a low $\mathrm{pH}$ (1.4) and it is more hydrophilic than One-Up Bond $\mathrm{F}$ ( $\mathrm{pH}$ 2.6). Both characteristics are responsible for the poor results of bond strength without application of the low-viscosity resin. ${ }^{6,11}$ The Tyrian SPE/ One-Step Plus system is considered a two-step selfetching primer adhesive. However, the SPE primer is a strong self-etching solution with a very low $\mathrm{pH}$ $(0.5)$ and the primer's hydrophilicity is increased by the application of the One-Step Plus bonding agent, which contains HEMA, BPDM and acetone, instead of purely hydrophobic adhesive resin. For the AdheSE, Clearfil Protect Bond and Unifil Bond systems, the hydrophilicity of the primers is reduced with the hydrophobic adhesive resin application, forming a combination of components from primer 
and hydrophobic resin to be copolymerized with the light-curing unit. However, a significant increase in bond strength was observed when the low-viscosity resin was applied over the bonded dentin for all categories of adhesive systems tested (etch \& rinse simplified; one-step self-etching and 2-step self-etching systems).

The resin coating may reduce the permeability and improve the long term durability of the hybrid layer. ${ }^{2,7,11}$ The additional application of a hydrophobic low viscosity resin over the hybridized dentin may improve the polymerization process of the adhesive system. The uncured resin or acidic monomers from the oxygen inhibition layer may subsequently polymerize with the diffusion of free radicals from the low viscosity resin. ${ }^{10}$ Also, the low-viscosity composite liner can act as an absorbing layer protecting the adhesive layer against the contraction stress generated during the resin cement polymerization $^{12}$ and can modify the failure pattern (Figure 4) as previously described. ${ }^{10,12}$ Due to the formation of

\section{References}

1. Jayasooriya PR, Pereira PN, Nikaido T, Burrow MF, Tagami J. The effect of a "resin coating" on the interfacial adaptation of composite inlays. Oper Dent. 2003;28(1):28-35.

2. Jayasooriya PR, Pereira PN, Nikaido T, Tagami J. Efficacy of a resin coating on bond strengths of resin cement to dentin. J Esthet Restor Dent. 2003;15(2):105-13.

3. Markus BB. Long-term clinical success of all-ceramic posterior restorations. Quintessence Int. 2002;33(3):415-26.

4. Giannini M, de Goes MF, Nikaido T, Shimada Y, Tagami J. Influence of activation mode of dual-cured resin composite cores and low-viscosity composite liners on bond strength to dentin treated with self-etching adhesives. J Adhes Dent. 2004;6(4):301-6.

5. Sanares AME, Itthagarun A, King NM, Tay FR, Pashley $\mathrm{DH}$. Adverse surface interactions between one-bottle lightcured adhesives and chemical-cured composites. Dent Mater. 2001;17(6):542-56.

6. Tay FR, Pashley DH. Have dentin adhesives become too hydrophilic? J Can Dent Assoc. 2003;69(11):726-31.

7. Nikaido T, Cho E, Nakajima M, Tashiro H, Toba S, Burrow MF et al. Tensile bond strengths of resin cements to bovine dentin using resin coating. Am J Dent. 2003;16(Spec No):41A-46A. a stronger hybridization process, the fracture tends to preserve the bonded interface area. Conversely, for groups without the low-viscosity resin, the fractures involved adhesive failure and partial cohesive failure in resin cement (Figure 3) or partial in dentin (Figure 5). Cohesive failures in dentin were observed in all groups, since bonded specimens develop nonuniform stress distributions during shear bond testing, leading to failures of the dentin substrate at stresses far below its ultimate strength. ${ }^{13}$

\section{Conclusion}

The results of the present study suggest that the bond strength of resin cements to dentin using adhesive systems can be improved if a low-viscosity composite liner and the resin coating technique are used.

\section{Acknowledgments}

This study was partially supported by grants n. 301769/2004-4 from CNPq and n. 03/08090-7 from FAPESP, Brazil.

8. Reis AF, Arrais CA, Novaes PD, Carvalho RM, De Goes MF, Giannini M. Ultramorphological analysis of resin-dentin interfaces produced with water-based single-step and two-step adhesives: nanoleakage expression. J Biomed Mater Res B Appl Biomater. 2004;71(1):90-8.

9. Shimada Y, Yamaguchi S, Tagami J. Micro-shear bond strength of dual-cured resin cement to glass ceramics. Dent Mater. 2002;18(5):380-8.

10. De Goes MF, Giannini M, Rueggeberg FA. Conversion of dentin bonding agents mixed with composite [abstract]. J Dent Res. 2004;83:556.

11. Carvalho RM, Pegoraro TA, Tay FR, Pegoraro LF, Silva NRFA, Pashley DH. Adhesive permeability affects coupling of resin cements that utilise self-etching primers to dentine. J Dent. 2004;32(1):55-65.

12. Reis AF, Giannini M, Ambrosano GMB, Chan DCN. The effects of filling techniques and a low-viscosity composite liner on bond strength to class II cavities. J Dent. 2003;31(1):5966.

13. Van Noort R, Howard IC, Cardew G. A critique of bond strength measurement. J Dent. 1989;17(2):61-7. 